Paidéia, 2005, 15(31), 217-226

\title{
ESTUDO COMPARATIVO DAS CARACTERÍSTICAS DO AMBIENTE FAMILIAR DE CRIANÇAS COM ALTO E BAIXO RENDIMENTO ACADÊMICO ${ }^{1}$
}

\author{
Patricia Leila dos Santos ${ }^{2}$ \\ FMRP - Universidade de São Paulo \\ Sônia Santa Vitaliano Graminha \\ FFCLRP - Universidade de São Paulo
}

\begin{abstract}
Resumo: O objetivo deste trabalho foi identificar diferentes aspectos do contexto familiar, desde nível sócio-econômico (NSE) até as expectativas com relação ao futuro das crianças, que possam influenciar o rendimento acadêmico das mesmas. Para isto, a amostra foi composta por dois grupos com 20 crianças cada: um grupo com baixo rendimento acadêmico (BRA) e outro com alto rendimento (ARA). Utilizou-se um formulário para investigar o NSE, escolaridade dos pais e estrutura familiar e um roteiro de entrevista para investigar a história de desenvolvimento da criança. Os resultados mostram que, de modo geral, o ambiente familiar das crianças do grupo BRA tende a apresentar um número maior de adversidades desde a concepção dessas crianças e essas famílias apresentam NSE e escolaridade mais baixos. Em contrapartida, as famílias do grupo ARA oferecem mais materiais e estímulos para o desenvolvimento das crianças e as mães participam mais das reuniões escolares.
\end{abstract}

Palavras-chave: rendimento acadêmico; ambiente familiar; escolares; dificuldades de aprendizagem; fatores de risco.

\section{COMPARATIVE STUDY OF FAMILY ENVIRONMENT CHARACTERISTICS OF CHILDREN WITH HIGH AND LOW ACADEMIC PERFORMANCE}

\begin{abstract}
The purpose of this study was to identify different aspects of family context, ranging from the socioeconomic level (SEL) up to the expectations regarding the future of the children, which might be influencing their academic performance. For such purpose, the studied population consisted of two groups of 20 children each: a low academic performance (LAP) group and a high academic performance (HAP) group. A questionnaire was used to assess the SEL, parents' schooling and family structure, and an interview form investigated the child's developmental history. The results show that, overall, the family environment of children from the LAP group tend to exhibit a greater number of misfortunes ever since their conception and their families present lower SEL and schooling. On the other hand, families of the children from the HAP group provide more material support and stimulation for development of the children. In addition, their mothers have greater participation in the parents-teachers meetings.
\end{abstract}

Key-words: academic performance; family environment; schoolchildren; learning difficulties; risk factors.

Introdução; Estudos sobre condições de risco e vulnerabilidade têm enfocado três conjuntos de variáveis operando como risco ou proteção: as características de personalidade e do contexto pessoal da

\footnotetext{
${ }^{1}$ Recebido para publicação em 17/02/2005 e aceito em 16/05/2005. 2 Endereço para correspondência: Patrícia Leila dos Santos, Departamento de Neurologia, Psiquiatria e Psicologia Médica da Faculdade de Medicina de Ribeirão Preto da Universidade de São Paulo, Avenida Bandeirantes, 3900, Ribeirão Preto-SP, CEP: 14048900, E-mail: plsantos@fmrp.usp.br
}

criança; as características do ambiente familiar e as do ambiente social mais amplo, incluindo escola e comunidade (Farran \& Cooper, 1986; Lewis, Duglokinski, Caputo \& Griffin, 1988; Graminha, Martins \& Miura, 1996).

Essas variáveis interagem determinando o rumo do desenvolvimento humano, podendo ora facilitar ora prejudicar o indivíduo e suas capacidades. No contexto da aprendizagem, observa-se que, tanto fatores 


\section{Patricia Leila dos Santos}

orgânicos quanto psicológicos e ambientais interferem no rendimento da criança, destacando-se o papel da família no bom desenvolvimento e interação da criança com as questões escolares (Weiss, 1997).

A exposição ao risco na dimensão familiar pode se iniciar desde a gestação, incluindo o fato de a criança ter sido ou não desejada, de que a mãe era muito jovem ou adolescente e mesmo solteira na época da gravidez. Insere-se também neste contexto, a adoção, dificuldades financeiras, problemas de saúde física dos membros da família, de saúde mental dos pais, consumo de álcool e/ou droga por eles, morte de algum membro, nascimento de um irmão, conflitos conjugais, separação dos pais, mudança de cidade ou residência, insegurança e/ou inconsistência dos pais, superproteção, indiferença e rejeição e agressividade física ou verbal dos pais com a criança (Marturano, Magna \& Murtha, 1993; Vickers, 1994; Graminha \& cols., 1996).

Vickers (1994), em um estudo sobre diferenças de funcionamento de famílias de crianças em risco de evasão escolar, encontrou que estas eram freqüentemente provenientes de famílias pobres, que contavam com a presença de apenas um dos pais, cujos genitores haviam se evadido da escola, sendo que a maioria apresentava uma dinâmica de funcionamento desengajada, com baixa coesão entre os membros, baixo nível de adaptação familiar diante de diferentes situações. Em contrapartida, as do grupo de comparação eram mais coesas e flexíveis quanto aos papéis e decisões familiares.

Outras variáveis, tais como responsividade dos pais, aceitação da criança, organização da casa, disponibilidade de brinquedos e variedade de materiais e, envolvimento e participação dos pais com a criança, mostram correlações significativas com desempenho acadêmico e resultados cognitivos e motores infantis (Bradley, Caldwell \& Rock, 1988; Bendersky \& Lewis, 1994). A participação e o envolvimento dos pais na escola também têm se mostrado uma variável importante relacionada ao desempenho escolar infantil (Reynolds \& Bezruczko, 1993; Santos, 2002).

Ainda sobre a família, um estudo de Benasich e Brooks-Gunn (1996) relativo à influência do conhecimento dos pais a respeito de desenvolvimento e educação infantis, indicou que estas variáveis fornecem uma base para a organização do ambiente da casa que, por sua vez, influencia os resultados desenvolvimentais da criança.

Baldwin, Baldwin e Cole (1990), buscando distinguir entre crianças e famílias resistentes ao stress, utilizaram como variáveis de risco o baixo nível ocupacional e educacional dos pais, a condição de minoria racial e a ausência do pai, e encontraram que nas de alto risco cujos filhos obtiveram sucesso em termos cognitivos, elas eram mais restritivas, puniam mais severamente suas crianças, tinham maior clareza na colocação e explicação de regras e, em contrapartida, eram menos democráticas e justificavam menos sua política educacional do que as de baixo risco. Tais resultados sugerem que as práticas educativas podem se apresentar como fatores de proteção para crianças de famílias de alto risco.

Em seu estudo sobre as condições de desenvolvimento, antecedentes à entrada na primeira série, associadas ao atraso escolar, Magna (1997) incluiu os aspectos sócio-econômico-educacionais, eventos adversos no ambiente familiar, antecedentes familiares de dificuldades de aprendizagem e de linguagem, como fatores de risco no contexto ambiental e encontrou que grande parte das crianças vivia sob condições sócio-econômicas desfavoráveis; em muitas famílias havia história de três ou mais mudanças de emprego do pai e também de residência; em outras, as crianças tinham experienciado o nascimento de um irmão mais novo, hospitalização ou doença de um dos pais, pessoas nervosas e/ou com doença crônica na família nuclear e um dos pais alcoolista. Além disso, na maioria das famílias havia antecedentes de dificuldade de aprendizagem e, em cerca um terço da amostra, antecedente de dificuldade de fala.

As condições sócio-econômicas, caracterizadas por pobreza e miserabilidade, também têm sido apontadas como fator de risco importante, inclusive porque muitas vezes expõem as crianças a altos níveis de violência na vizinhança. Em contrapartida, as fontes de apoio social, sejam da família extensa ou da vizinhança e da religião tendem a contribuir para melhores resultados infantis (Lewis \& cols., 1988; Baldwin \& cols., 1990; Reynolds \& Bezruczko, 1993; Speakman, Herman \& Vogel, 1993).

Entre as variáveis apontadas como recursos que podem favorecer o desenvolvimento encontramse: recursos materiais da casa, conteúdos ensinados 
à criança, atividades de lazer, participação em instituição pré-escolar, aspiração dos pais quanto à escolarização do filho, valorização do estudo, conhecimento do sistema educacional pelos pais, organização do ambiente familiar e práticas educativas (Magna, 1997; Marturano, 1999; Bradley \& Corwyn, 2002).

Levando em conta o papel de destaque da família e do ambiente doméstico no desenvolvimento da criança, este estudo foi desenvolvido com o objetivo de identificar diferenças em características do contexto familiar que possam influenciar o rendimento acadêmico das crianças, incluindo: condições sócio-econômica-educacionais; estrutura e relacionamento familiar; condições de gestação; participação da família na vida escolar das crianças; problemas de saúde física e/ou mental na família; práticas educativas; expectativas sobre o desenvolvimento da criança e recursos do ambiente familiar.

\section{Metodologia}

De um total de 329 alunos de primeira e segunda séries do $1^{\circ}$ grau da Rede de Ensino Estadual da cidade de Ribeirão Preto, foi selecionada, para este estudo, uma amostra de crianças, a partir de avaliações do professor sobre o rendimento acadêmico de seus alunos, de forma a constituir dois grupos de pesquisa: um com baixo rendimento acadêmico (BRA) e outro com alto rendimento (ARA).

Foi solicitado aos professores que avaliassem o rendimento de seus alunos dentro de uma escala de 1 a 10; de posse desses dados, selecionaram-se, aleatoriamente, 20 crianças classificadas pelo professor nos pontos 1 ou 2 para comporem o grupo BRA (baixo rendimento acadêmico) e 20 avaliados nos pontos 9 ou 10 para o grupo ARA (alto rendimento acadêmico).

O grupo BRA ficou composto por crianças com idades variando entre seis anos e 11 meses a 10 anos e 10 meses, sendo $75 \%$ meninos e $25 \%$ meninas, $40 \%$ alunos da $1^{\text {a }}$. série e $60 \%$ da $2^{\text {a }}$. série (Tabela 1 ).

No grupo ARA as idades variaram entre seis anos e 11 meses a nove anos e 10 meses, sendo $40 \%$ meninos e $60 \%$ meninas, $50 \%$ alunos da $1^{\text {a }}$. série e $50 \%$ da $2^{\mathrm{a}}$. série.

Os dados foram coletados junto às mães através de dois instrumentos: um Formulário Informativo sobre Condição Sócio-Econômica-Educacional e Estrutura Familiar e um Roteiro de Entrevista sobre Con- dições de Desenvolvimento da Criança, ambos elaborados para um estudo mais amplo sobre condições de risco e recursos associados ao baixo e alto rendimento acadêmico (Santos, 2002).

O formulário contém nove questões que têm por objetivo o levantamento de informações sobre situação econômica, escolaridade e profissão dos pais e estrutura familiar. O roteiro de entrevista contém 151 questões abertas e tem por objetivo levantar junto às mães o máximo de informações possíveis sobre desenvolvimento, funcionamento atual da criança, formas de enfrentamento dos eventos desenvolvimentais, bem como estressores, condições adversas e favoráveis, incluindo tanto situações do contexto pessoal quanto ambiental das crianças.

Após a seleção da amostra foi encaminhada uma carta às mães, convidando-as para participarem da pesquisa e agendando um horário para entrevista (em caso de concordância); juntamente, foi enviado o Formulário sobre Nível Sócio-Econômico para ser preenchido por elas e devolvido ao pesquisador no dia da entrevista.

As informações contidas no Formulário sobre Nível Sócio-Econômico foram tabuladas, calculandose as porcentagens de respostas a cada item do formulário e as respostas às questões das entrevistas classificadas de acordo com um sistema de categorias elaborado para esta finalidade, tabulando-se os dados e calculando-se também as freqüências e porcentagens.

Procedeu-se à análise estatística dos dados da entrevista para verificar as diferenças significativas entre o grupo BRA e ARA, através do programa SPSS (versão 10.0), aplicando-se o Qui-quadrado de Pearson ou o Teste Exato de Fisher (dependendo da freqüência esperada). Tomou-se como significativo os resultados em que $\mathrm{p}<0,05$.

\section{Resultados}

Os dados mostram algumas diferenças significativas entre os dois grupos, sendo que, dentre elas, predominam para o grupo ARA: possuir casa própria, mães com $2^{\circ}$ grau completo, ter videocassete, telefone e eletrodomésticos de cozinha na casa. Para o grupo BRA, foi significativamente maior a ocorrência de mães com $1^{\circ}$ grau incompleto. Os resultados acham-se na Tabela 1. 


\section{Patricia Leila dos Santos}

Tabela 1. Condições sócio-econômica-educacionais das famílias das crianças do grupo BRA (18 sujeitos ${ }^{1}$ ) e do grupo ARA (19 sujeitos ${ }^{1}$ ) - valores em porcentagem e resultados da análise de significância.

\begin{tabular}{|c|c|c|c|}
\hline Variáveis & $\begin{array}{c}\text { Grupo } \\
\text { BRA }\end{array}$ & $\begin{array}{c}\text { Grupo } \\
\text { ARA }\end{array}$ & $\mathrm{p}$ \\
\hline $\begin{array}{l}\text { Mudança de residência } \\
\text { nos últimos dois anos: } 0 \\
1 \\
2\end{array}$ & $\begin{array}{l}55 \\
22 \\
22\end{array}$ & $\begin{array}{l}68 \\
16 \\
16\end{array}$ & $\begin{array}{l}0.420 \\
0.693 \\
0.693\end{array}$ \\
\hline $\begin{array}{l}\text { Residência:própria } \\
\text { alugada } \\
\text { emprestada } \\
\text { favela }\end{array}$ & $\begin{array}{r}33 \\
33 \\
28 \\
5\end{array}$ & $\begin{array}{r}68 \\
26 \\
5 \\
0\end{array}$ & $\begin{array}{l}0.033^{*} \\
0.641 \\
0.090 \\
0.486\end{array}$ \\
\hline $\begin{array}{l}\text { Renda familiar: } \\
\text { até } 1 \text { salário mínimo } \\
\text { entre } 1 \text { e } 5 \text { salários } \\
\text { entre } 5 \text { e } 10 \text { salários } \\
\text { acima de } 10 \text { salários }\end{array}$ & $\begin{array}{r}11 \\
72 \\
17 \\
0\end{array}$ & $\begin{array}{r}5 \\
53 \\
31 \\
10\end{array}$ & $\begin{array}{l}0.604 \\
0.219 \\
0.447 \\
0.486\end{array}$ \\
\hline $\begin{array}{l}\text { Escolaridade da mãe: } \\
\text { analfabeta } \\
1^{\circ} \text { grau incompleto } \\
1^{\circ} \text { grau completo } \\
2^{\circ} \text { grau incompleto } \\
2^{\circ} \text { grau completo } \\
\text { superior completo } \\
\text { sem informação }\end{array}$ & $\begin{array}{r}5 \\
83 \\
5 \\
5 \\
0 \\
0 \\
0\end{array}$ & $\begin{array}{r}0 \\
31 \\
10 \\
21 \\
26 \\
5 \\
5\end{array}$ & $\begin{array}{l}0.486 \\
0.001^{*} \\
1.000 \\
0.340 \\
0.046^{*} \\
1.000 \\
1.000\end{array}$ \\
\hline $\begin{array}{l}\text { Escolaridade do pai: } \\
\text { analfabeto } \\
1^{\circ} \text { grau incompleto } \\
1^{\circ} \text { grau completo } \\
2^{\circ} \text { grau incompleto } \\
2^{\circ} \text { grau completo } \\
\text { sem informação }{ }^{2}\end{array}$ & $\begin{array}{r}5 \\
55 \\
5 \\
0 \\
5 \\
28\end{array}$ & $\begin{array}{r}5 \\
37 \\
16 \\
10 \\
31 \\
0\end{array}$ & $\begin{array}{l}1.000 \\
0.254 \\
0.604 \\
0.486 \\
0.052 \\
0.020^{*}\end{array}$ \\
\hline $\begin{array}{l}\text { Profissão da mãe: } \\
\text { não qualificada } \\
\text { qualificação inferior } \\
\text { qualificação média } \\
\text { qualificação superior } \\
\text { desempregada } \\
\text { do lar }\end{array}$ & $\begin{array}{r}39 \\
11 \\
0 \\
0 \\
5 \\
44\end{array}$ & $\begin{array}{r}10 \\
21 \\
16 \\
5 \\
10 \\
37\end{array}$ & $\begin{array}{l}0.051 \\
0.660 \\
0.230 \\
1.000 \\
1.000 \\
0.638\end{array}$ \\
\hline $\begin{array}{l}\text { Profissão do pai: } \\
\text { não qualificada } \\
\text { qualificação inferior } \\
\text { qualificação média } \\
\text { desempregado } \\
\text { aposentado } \\
\text { sem informação }{ }^{2}\end{array}$ & $\begin{array}{r}44 \\
22 \\
0 \\
0 \\
5 \\
28\end{array}$ & $\begin{array}{r}16 \\
42 \\
21 \\
10 \\
10 \\
0\end{array}$ & $\begin{array}{l}0.057 \\
0.197 \\
0.059 \\
0.486 \\
1.000 \\
0.020 *\end{array}$ \\
\hline $\begin{array}{l}\text { Recursos da casa: } \\
\text { televisão } \\
\text { aparelho de som } \\
\text { videocassete } \\
\text { telefone } \\
\text { máq/ lavar/tanquinho } \\
\text { pelo menos 3eletr.de coz } \\
\text { convênio de saúde }\end{array}$ & $\begin{array}{r}100 \\
72 \\
22 \\
11 \\
61 \\
44 \\
22\end{array}$ & $\begin{array}{l}95 \\
74 \\
58 \\
63 \\
89 \\
89 \\
26\end{array}$ & $\begin{array}{l}1.000 \\
0.920 \\
0.027^{*} \\
0.001 * \\
0.051 \\
0.003^{*} \\
1.000\end{array}$ \\
\hline
\end{tabular}

1 Faltam informações de três famílias que não devolveram os formulários.

2 Para o grupo BRA, a ausência de informações quanto a escolaridade e profissão do pai $(28 \%)$ ocorreu devido à presença de casos de mães solteiras, viuvez ou abandono pelos pais.

*diferença significativa $(\mathrm{p}<0.05)$
De modo geral, observa-se que entre as famílias das crianças do grupo BRA encontra-se um percentual maior que mora em casas alugadas, emprestadas ou em barracos de favela (33\%, 28\% e $5 \%$, respectivamente), a grande maioria (83\%) com renda familiar inferior a cinco salários mínimos. Já no grupo ARA, a maioria (68\%) mora em casa própria, com renda familiar até cinco salários (58\%), mas há um percentual alto (41\%) de famílias com renda superior a cinco salários-mínimos.

Com relação à escolaridade e profissão dos pais, predominam no grupo BRA pais que têm o $1^{\circ}$ grau incompleto e com profissões não qualificadas ou de qualificação inferior; entre as mães o predomínio é das que não trabalham fora. O mesmo ocorre no grupo ARA, no entanto, aparecem também pais com escolaridade secundária e superior e profissões de qualificação média e superior.

Quanto aos recursos da casa, que dão pistas sobre o conforto da mesma, nos dois grupos encontra-se certa variedade, ainda que as famílias do ARA apresentem com maior freqüência todos os itens investigados, exceto a televisão.

Os dados da estrutura e relacionamento dos dois grupos estão na Tabela 2.

Tabela 2. Estrutura e relacionamento familiar das famílias das crianças dos grupos BRA $(\mathrm{N}=20)$ e ARA $(\mathrm{N}=20)$ - valores em porcentagem e resultados da análise de significância.

\begin{tabular}{|c|c|c|c|}
\hline Variáveis & $\begin{array}{c}\text { Grupo } \\
\text { BRA }\end{array}$ & $\begin{array}{l}\text { Grupo } \\
\text { ARA }\end{array}$ & $\mathrm{p}$ \\
\hline $\begin{array}{r}\text { Número de filhos }^{1}: \\
1 \\
2 / 3 \\
4 / 5 \\
6 / 7\end{array}$ & $\begin{array}{r}11 \\
39 \\
44 \\
5\end{array}$ & $\begin{array}{r}5 \\
68 \\
21 \\
5\end{array}$ & $\begin{array}{l}0.604 \\
0.072 \\
0.129 \\
1.000\end{array}$ \\
\hline $\begin{array}{r}\text { Número de pessoas } \\
\text { residentes na casa }{ }^{1}: \\
3 / 4 \\
5 / 6 \\
7 / 8 \\
9 / 10\end{array}$ & $\begin{array}{r}0 \\
22 \\
50 \\
17 \\
5 \\
5\end{array}$ & $\begin{array}{r}10 \\
53 \\
21 \\
10 \\
5 \\
0\end{array}$ & $\begin{array}{l}0.486 \\
0.057 \\
0.065 \\
0.660 \\
1.000 \\
0.486\end{array}$ \\
\hline $\begin{array}{l}\text { Pais separados } \\
\text { Criança não mora c.os pais } \\
\text { Mãe é viúva }\end{array}$ & $\begin{array}{r}40 \\
10 \\
5\end{array}$ & $\begin{array}{r}20 \\
0 \\
0\end{array}$ & $\begin{array}{l}0.168 \\
0.487 \\
1.000\end{array}$ \\
\hline
\end{tabular}


Estudo comparativo das Características do Ambiente 221

\begin{tabular}{|c|c|c|c|}
\hline Variáveis & $\begin{array}{l}\text { Grupo } \\
\text { BRA }\end{array}$ & $\begin{array}{l}\text { Grupo } \\
\text { ARA }\end{array}$ & $\mathrm{p}$ \\
\hline \multicolumn{4}{|l|}{$\begin{array}{l}\text { Como é o relacionamento } \\
\text { dos pais/substitutos (casal) }\end{array}$} \\
\hline -bom/normal/sem brigas & 75 & 65 & 0.490 \\
\hline -não se dão bem/brigam muito & 5 & 15 & 0.605 \\
\hline $\begin{array}{l}\text {-pais separados e não se dão bem } \\
\text {-pais separados, mas têm }\end{array}$ & 10 & 0 & 0.487 \\
\hline um bom relacionamento & 0 & 15 & 0.231 \\
\hline \multicolumn{4}{|l|}{$\begin{array}{l}\text { Relacionamento da criança } \\
\text { com os membros da família }\end{array}$} \\
\hline \multicolumn{2}{|c|}{$\begin{array}{l}\text {-bom/normal/ótimo/excelente } 45 \\
\text {-bom no geral, mas conflituoso }\end{array}$} & 75 & 0.105 \\
\hline $\begin{array}{l}\text { com um membro da família } \\
\text {-bom no geral, mas é }\end{array}$ & 40 & 20 & 0.168 \\
\hline um pouco brigona & 10 & 0 & 0.487 \\
\hline -sem relato & 0 & 5 & 1.000 \\
\hline $\begin{array}{l}\text { Criança já presenciou brigas/ } \\
\text { discussões em casa }\end{array}$ & S/ 75 & 80 & 1.000 \\
\hline
\end{tabular}

1 Para estes itens o grupo BRA tem $\mathrm{N}=18$ e o grupo ARA tem $\mathrm{N}=19$ devido à falta de informações de três famílias.

Predominam para os dois grupos as famílias com 2 a 5 filhos (83\% no grupo BRA e 89\% no ARA) e, em geral, o relacionamento familiar é descrito como bom (75\% das famílias do grupo BRA e 65\% do grupo ARA).

Os resultados sobre as condições de gestação das crianças estão na Tabela 3.

Tabela 3. Condições de gestação das crianças dos grupos BRA $(\mathrm{N}=20)$ e ARA $(\mathrm{N}=20)$ - valores em porcentagem e resultados da análise de significância.

\begin{tabular}{|c|c|c|c|}
\hline Variáveis & $\begin{array}{c}\text { Grupo } \\
\text { BRA }\end{array}$ & $\begin{array}{c}\text { Grupo } \\
\text { ARA } \\
\end{array}$ & $\mathrm{p}$ \\
\hline \multicolumn{3}{|l|}{ Idade da mãe quando } & $0.022 *$ \\
\hline $21-30$ anos & 15 & 40 & 0.077 \\
\hline $31-43$ anos & 30 & 40 & 0.507 \\
\hline sem informação & 5 & 0 & 1.000 \\
\hline \multicolumn{4}{|l|}{ Situação conjugal quando } \\
\hline engravidou: solteira & 30 & 20 & 0.465 \\
\hline casada & 25 & 65 & $0.011 *$ \\
\hline amasiada & 45 & 15 & $0.038 *$ \\
\hline Gravidez não planejada & 90 & 65 & 0.127 \\
\hline Reação neg. da mãe à gest. & 25 & 10 & 0.407 \\
\hline Reação neg. do pai à gest. & 40 & 15 & 0.077 \\
\hline Reação neg. de um ou mais fam & 45 & 30 & 0.327 \\
\hline \multicolumn{4}{|l|}{ Posição da criança na ordem } \\
\hline das gestações: $1^{\mathrm{a}}$ ou $2^{\mathrm{a}}$ & 70 & 60 & 0.507 \\
\hline $3^{\mathrm{a}}$ ou $4^{\mathrm{a}}$ & 20 & 30 & 0.465 \\
\hline
\end{tabular}

\begin{tabular}{crcc}
\hline \multicolumn{1}{c}{ Variáveis } & $\begin{array}{c}\text { Grupo } \\
\text { BRA }\end{array}$ & $\begin{array}{c}\text { Grupo } \\
\text { ARA }\end{array}$ & $\mathrm{p}$ \\
\hline 5 ${ }^{\mathrm{a}}$ ou 6 \\
a & 5 & 10 & 1.000 \\
sem informação & 5 & 0 & 1.000 \\
Mãe fez trat. pré-natal & 85 & 100 & 0.231 \\
Houveintercorrênciasna gest. & 65 & 55 & 0.519 \\
$\begin{array}{c}\text { Número de intercorrências } \\
\text { na gestação:1 - 2 }\end{array}$ & 55 & 45 & 0.527 \\
3 - 5 & 5 & 5 & 1.000 \\
10 ou mais & 5 & 5 & 1.000 \\
\hline
\end{tabular}

* diferença significativa $(\mathrm{p}<0.05)$

Esses resultados evidenciam que foi significativamente maior para o grupo BRA a porcentagem de mães que engravidaram entre 16 e 20 anos e também de amasiadas. Para o grupo ARA foi significativamente maior a ocorrência de mães já casadas na época da concepção.

Embora as diferenças entre os dois grupos não sejam significativas, vale apontar que os itens: gravidez não planejada, reação negativa da mãe, do pai e de outros familiares à gestação, a criança ser fruto da primeira ou segunda gestação da mãe e intercorrências gestacionais ocorreram mais no grupo BRA, bem como foi menor neste grupo a porcentagem de mães que realizou acompanhamento prénatal.

A Tabela 4 traz a participação da família na escola e nas atividades escolares da criança.

Tabela 4. Participação da família na escola e atividades escolares das crianças dos grupos BRA $(\mathrm{N}=20)$ e ARA $(\mathrm{N}=20)$ - valores em porcentagem e resultados da análise de significância.

\begin{tabular}{crcc}
\hline \multicolumn{1}{c}{ Variáveis } & $\begin{array}{c}\text { Grupo } \\
\text { BRA }\end{array}$ & $\begin{array}{c}\text { Grupo } \\
\text { ARA }\end{array}$ & $\mathrm{p}$ \\
\hline $\begin{array}{c}\text { Quem lembra a criança } \\
\text { para fazer a tarefa: mãe } \\
\text { pai }\end{array}$ & 50 & 25 & 0.102 \\
outros & 15 & 10 & 1.000 \\
& & & 1.000 \\
\hline $\begin{array}{c}\text { Quem ajuda a criança a fazer } \\
\text { a tarefa quando ela precisa: } \\
\text { mãe } \\
\text { pai }\end{array}$ & 70 & 60 & 0.507 \\
outros & 30 & 15 & 0.231 \\
ninguém & 10 & 0 & 0.465 \\
& & & 0.487 \\
\hline & & & Continua-
\end{tabular}


222 Patricia Leila dos Santos

\begin{tabular}{lrcl}
\hline \multicolumn{1}{c}{ Variáveis } & $\begin{array}{c}\text { Grupo } \\
\text { BRA }\end{array}$ & $\begin{array}{c}\text { Grupo } \\
\text { ARA }\end{array}$ & $\mathrm{p}$ \\
\hline $\begin{array}{l}\text { Família frequenta } \\
\text { reuniões escolares: }\end{array}$ & & & \\
& 65 & 95 & 0.078 \\
$\begin{array}{l}\text { Quem vai às reuniões: mãe } \\
\text { pai }\end{array}$ & 55 & 85 & $0.038^{*}$ \\
outros & 20 & 15 & 0.605 \\
& & 15 & 1.000 \\
\hline
\end{tabular}

* diferença significativa $(\mathrm{p}<0.05)$

Nota-se, de modo geral, que a mãe é quem geralmente acompanha tanto as tarefas quanto as reuniões escolares. A participação das do grupo ARA nas reuniões escolares é significativamente maior que do grupo BRA.

Os resultados sobre as práticas educativas encontram-se na Tabela 5.

Tabela 5. Práticas educativas das famílias das crianças dos grupos BRA ( $\mathrm{N}=20)$ e ARA $(\mathrm{N}=20)$ - valores em porcentagem e resultados da análise de significância.

\begin{tabular}{|c|c|c|c|}
\hline Variáveis & $\begin{array}{l}\text { Grupo } \\
\text { BRA }\end{array}$ & $\begin{array}{l}\text { Grupo } \\
\text { ARA }\end{array}$ & $\mathrm{p}$ \\
\hline Criança é criticada em casa & 60 & 60 & 1.000 \\
\hline Criança apanha & 75 & 65 & 0.490 \\
\hline Criança recebe castigo & 60 & 45 & 0.342 \\
\hline Criança é elogiada & 90 & 85 & 1.000 \\
\hline $\begin{array}{l}\text { Criança é orientada, explica-s } \\
\text { a ela o que é certo/errado }\end{array}$ & se 95 & 100 & 1.000 \\
\hline $\begin{array}{l}\text { Comportamentos da criança } \\
\text { costumam ser ignorados }\end{array}$ & 35 & 35 & 1.000 \\
\hline $\begin{array}{l}\text { A criança é informada quanc } \\
\text { a família está com problema }\end{array}$ & ldo 65 & 75 & 0.490 \\
\hline $\begin{array}{l}\text { A criança pode opinar sobre } \\
\text { as decisões familiares }\end{array}$ & 20 & 20 & 1.000 \\
\hline
\end{tabular}

No que diz respeito às práticas educativas, os resultados não mostram diferenças significativas nos dois grupos de famílias. Entretanto, as famílias do grupo BRA tendem a usar um pouco mais da punição física e de castigos, embora nos dois grupos predomine a prática de orientar e dar explicações sobre certo/ errado para educar a criança. Nota-se também que as famílias do grupo ARA costumam comunicar os problemas familiares às crianças com maior freqüência.

A Tabela 6 traz os resultados referentes a problemas de saúde física, mental e com a polícia.
Tabela 6. Problemas de saúde física e/ou mental nas famílias das crianças dos grupos BRA ( $N=20)$ e ARA $(\mathrm{N}=20)$ - valores em porcentagem e resultados da análise de significância.

\begin{tabular}{|c|c|c|c|}
\hline Variáveis & $\begin{array}{l}\text { Grupo } \\
\text { BRA }\end{array}$ & $\begin{array}{l}\text { Grupo } \\
\text { ARA }\end{array}$ & $\mathrm{p}$ \\
\hline $\begin{array}{l}\text { Algum familiar próximo } \\
\text { tem prob. de saúde física }\end{array}$ & 45 & 65 & 0.204 \\
\hline $\begin{array}{l}\text { Problema de saúde física } \\
\text { do pai/mãe }\end{array}$ & 25 & 35 & 0.490 \\
\hline $\begin{array}{l}\text { Algum familiar tem prob. } \\
\text { de saúde mental }\end{array}$ & 30 & 25 & 0.723 \\
\hline $\begin{array}{l}\text { Doença mental do } \\
\text { pai ou mãe }\end{array}$ & 15 & 5 & 0.605 \\
\hline Algum fam. fuma/ já fumou & u 55 & 35 & 0.204 \\
\hline Pai/mãe fumante & 45 & 50 & 0.752 \\
\hline $\begin{array}{l}\text { Algum familiar bebe/ } \\
\text { ou já bebeü }\end{array}$ & 70 & 55 & 0.327 \\
\hline Alcoolismo do pai/mãe & 45 & 25 & 0.185 \\
\hline $\begin{array}{l}\text { Algum familiar usa/ } \\
\text { já usou drogas }\end{array}$ & 30 & 30 & 1.000 \\
\hline Drogadição do pai & 20 & 5 & 0.342 \\
\hline $\begin{array}{l}\text { Algum familiar tem o } \\
\text { hábito de jogar a dinheiro }\end{array}$ & 5 & 5 & 1.000 \\
\hline $\begin{array}{l}\text { Algum familiar ou pessoa } \\
\text { conhecida tem ou teve } \\
\text { problemas com a polícia }\end{array}$ & 55 & 20 & $0.022 *$ \\
\hline Pai está preso & 5 & 10 & 1.000 \\
\hline
\end{tabular}

\# 3 casos de alcoolismo no grupo BRA; 2 casos de alcoolismo no grupo ARA

* diferença significativa $(\mathrm{p}<0.05)$

Os resultados mostram que houve diferença significativa entre os dois grupos quanto a algum familiar ou pessoa conhecida ter problemas com a polícia, que ocorreu com maior incidência para o grupo BRA (55\% em BRA contra 20\% no ARA). Quanto aos outros problemas investigados, vale destacar que os de saúde mental e uso de bebidas alcoólicas tanto de familiares quanto dos pais e a drogadição do pai aparecem mais freqüentemente para o grupo BRA. Já, o item referente aos de saúde física na família ocorreu mais no grupo ARA.

Os dados sobre recursos ambientais disponíveis para a criança, acham-se na Tabela 7. 
Tabela 7. Recursos do ambiente das crianças dos grupos BRA $(\mathrm{N}=20)$ e ARA $(\mathrm{N}=20)$ - valores em porcentagem e resultados da análise de significância.

\begin{tabular}{|c|c|c|c|}
\hline Variáveis & $\begin{array}{l}\text { Grupo } \\
\text { BRA }\end{array}$ & $\begin{array}{l}\text { Grupo } \\
\text { ARA }\end{array}$ & $\mathrm{p}$ \\
\hline Bicicleta & 35 & 50 & 0.337 \\
\hline Patins & 35 & 55 & 0.204 \\
\hline Skate & 5 & 10 & 1.000 \\
\hline $\begin{array}{l}\text { Brinquedos em geral } \\
\text { (ou outros brinquedos) }\end{array}$ & 85 & 100 & 0.231 \\
\hline Videogame & 0 & 20 & 0.106 \\
\hline $\begin{array}{l}\text { Alguém da família brinca } \\
\text { junto com a criança }\end{array}$ & 70 & 50 & 0.197 \\
\hline Costuma fazer passeios & 45 & 70 & 0.110 \\
\hline Costuma fazer visitas & 50 & 60 & 0.525 \\
\hline Acompanha pais a compras & s 75 & 95 & 0.182 \\
\hline Tem/já teve animais em casa & 80 & 75 & 1.000 \\
\hline Tem material de leitura em casa & 100 & 100 & 1.000 \\
\hline Pai/mãe costumam ler & 50 & 55 & 0.752 \\
\hline $\begin{array}{l}\text { Criança tem material } \\
\text { de leitura próprio }\end{array}$ & 50 & 85 & $0.018 *$ \\
\hline $\begin{array}{l}\text { Alguém lê histórias } \\
\text { para a criança }\end{array}$ & 35 & 45 & 0.519 \\
\hline $\begin{array}{l}\text { Criança pede que leiam/ } \\
\text { contem histórias para ela }\end{array}$ & 45 & 60 & 0.342 \\
\hline $\begin{array}{l}\text { Possui material para pintar/ } \\
\text { colorir em casa }\end{array}$ & 65 & 100 & $0.008 *$ \\
\hline $\begin{array}{l}\text { Utiliza o material de } \\
\text { pintura em casa }\end{array}$ & 55 & 90 & $0.013 *$ \\
\hline Ouve músicas & 90 & 75 & 0.407 \\
\hline Assiste televisão & 95 & 100 & 1.000 \\
\hline A família tem religião & 90 & 95 & 1.000 \\
\hline $\begin{array}{l}\text { Criança frequenta } \\
\text { atividades religiosas }\end{array}$ & 45 & 75 & $0.053 *$ \\
\hline $\begin{array}{l}\text { Existe alguém que cuida da } \\
\text { criança na ausência dos pais } \\
\text { Criança fica sozinha }\end{array}$ & s 70 & 80 & 0.465 \\
\hline quando pais se ausentam & 15 & 5 & 0.605 \\
\hline Costuma ser levado ao médico & 100 & 100 & 1.000 \\
\hline Tomou todas as vacinas & 80 & 100 & 0.106 \\
\hline Já foi ao dentista & 90 & 95 & 1.000 \\
\hline
\end{tabular}

* diferença significativa $(\mathrm{p}<0.05)$

Os dados mostram que quatro itens diferenciaram significativamente os dois grupos, sempre com maior incidência no grupo ARA: a criança ter material de leitura próprio (85\% em ARA para 50\% em BRA), possuir material para pintar/colorir em casa (100\% contra 65\%), utilizar o material de pintura (90\% para $55 \%)$ e freqüentar atividades religiosas (75\% para $45 \%)$.

Dos 22 itens sobre recursos ambientais restantes, 16 também ocorreram com mais freqüência no grupo ARA, sendo que as maiores diferenças entre os dois grupos (entre 15\% e 25\%) são com relação aos itens: ter bicicleta, patins, skate, brinquedos em geral, videogame, fazer passeios, acompanhar os pais a compras, a criança pedir que leiam ou contem histórias para ela e ter tomado todas as vacinas.

Os itens em que a incidência é maior para o grupo BRA do que para o ARA, com diferenças entre $15 \%$ e $20 \%$ são: ter alguém da família que brinca junto com a criança e ouvir música.

A Tabela 8 permite observar os resultados quanto à visão de futuro dos filhos.

Tabela 8. Expectativas das mães quanto ao futuro das crianças dos grupos BRA (N=20) e ARA $(N=20)$ - valores em porcentagem e resultados da análise de significância.

\begin{tabular}{lccc}
\hline \multicolumn{1}{c}{ Expectativa } & $\begin{array}{c}\text { Grupo } \\
\text { BRA }\end{array}$ & $\begin{array}{c}\text { Grupo } \\
\text { ARA }\end{array}$ & $\mathrm{p}$ \\
\hline $\begin{array}{l}\text { Relacionada à } \\
\text { escolarização imediata }\end{array}$ & 35 & 5 & $0.044^{*}$ \\
$\begin{array}{l}\text { Relacionada à } \\
\text { escolarização futura }\end{array}$ & 15 & 65 & $0.001^{*}$ \\
$\begin{array}{l}\text { Preocupação em afastar } \\
\text { a criança de violência, }\end{array}$ & 25 & 0 & $0.047^{*}$ \\
$\begin{array}{l}\text { drogas, das ruas } \\
\begin{array}{l}\text { Relacionada a diferentes } \\
\text { dimensões (estudo, trabalho, }\end{array}\end{array}$ & & \\
$\begin{array}{l}\text { caráter, socialização) } \\
\begin{array}{l}\text { Falta de qualquer expectativa } \\
\text { (verbalizada pela mãe) }\end{array}\end{array}$ & 5 & 0 & 10.000 \\
$\begin{array}{l}\text { Expectativa de melhora, } \\
\text { sem especificação }\end{array}$ & 0 & 5 & 1.000 \\
$\begin{array}{l}\text { Expectativa relacionada à ter } \\
\text { uma vida melhor que a da mãe } \\
\text { (sem outra especificação) }\end{array}$ & 0 & 15 & 0.231 \\
\hline
\end{tabular}

* diferença significativa $(\mathrm{p}<0.05)$

No grupo BRA há uma porcentagem significativamente maior de mães cuja expectativa quanto ao futuro dos filhos está associada à escolarização imediata (35\% em BRA para 5\% em ARA) e também das que têm como principal preocupação afastar a criança da violência, das drogas e das ruas (25\% para 0). Em contrapartida, é significativamente maior no grupo ARA a incidência de mães cuja expectativa está relacionada à escolarização futura das crianças (65\% em ARA contra 15\% em BRA).

Para o grupo BRA também é maior a incidên- 


\section{Patricia Leila dos Santos}

cia de mães com expectativas relacionadas a diferentes dimensões da vida (estudo, trabalho, caráter, socialização) e apenas neste grupo aparece a falta de qualquer expectativa (verbalizada pela mãe).

\section{Discussão}

Os resultados deste trabalho apontam que desde a sua concepção crianças com baixo rendimento acadêmico estão inseridas em um contexto familiar mais adverso do que as que apresentam um bom desempenho na escola. Embora nem sempre a diferença observada nos dados tenha sido estatisticamente significativa, existe uma tendência das crianças com baixo rendimento de terem sido expostas a um número maior de adversidades que podem ter afetado seu desenvolvimento na escola.

Este panorama de adversidades começa a se esboçar desde a concepção. A história gestacional da amostra estudada evidencia que além de as mães de crianças do grupo BRA serem mais novas na época da concepção, elas tiveram uma gestação mais marcada por situações adversas, com destaque para as reações negativas tanto da mãe e do pai quanto de outros familiares, apontando, desde o início da gestação, para um contexto adverso para o desenvolvimento. Algumas crianças do grupo BRA de fato nasceram em ambientes muito desfavoráveis, com a presença de estressores psicossociais conhecidos (alcoolismo, drogadição e conflitos conjugais).

A alta porcentagem, no grupo de baixo rendimento, de mães amasiadas e solteiras na época da concepção sugere ainda a possibilidade de a gestação ter ocorrido num contexto instável ou, no mínimo, não preparado para receber a criança, o que talvez justifique também as reações negativas da mãe, pai e familiares dela. Por outro lado, o grupo de alto rendimento concentrou um número maior de mães casadas na época da concepção, o que sugere que a presença do companheiro pode significar uma fonte importante de apoio que favorece o desenvolvimento infantil, talvez por aumentar a disponibilidade de tempo e atenção dada à criança por parte da mãe e mesmo do pai.

Estes dados sugerem que baixo rendimento acadêmico seja uma das conseqüências de muitas outras falhas desenvolvimentais e adversidades ambientais que antecederam o período escolar, remetendo à idéia de reação em cadeia descrita por Rutter (1987) e reafir- mando a noção de que não é um fator de risco isoladamente o responsável por um mau resultado e sim a combinação de vários deles. Vale lembrar que na história de vida das crianças do grupo ARA também estão presentes condições adversas ao desenvolvimento, ainda que com menor incidência, contudo, a presença de fatores de risco nesses casos não foi suficiente para determinar mau resultado escolar.

Quanto aos resultados sobre nível sócio-econômico-educacional, eles corroboram dados da literatura (Wood, Halfon, Scarlata, Newacheck \& Nessim, 1993; Duncan, Brooks-Gunn \& Klebanov, 1994) ao evidenciarem que as famílias de crianças com BRA, comparadas com as de ARA, tendem a mudar de residência com maior freqüência, morando, na maioria das vezes, em casas alugadas ou emprestadas e apresentam, ainda, tendência a renda familiar inferior e moradias com menos conforto.

Os pais de crianças de BRA apresentam nível de escolaridade inferior aos das crianças de ARA, bem como têm, com maior freqüência, profissões não qualificadas.

A baixa escolaridade e qualificação profissional dos pais podem se estabelecer como risco, na medida em que as famílias têm menos condições de orientar e auxiliar os filhos academicamente e expectativas quanto ao seu estudo futuro, o que se evidencia nos dados em que os pais de crianças de BRA demonstram preocupações mais voltadas à formação de seus filhos enquanto pessoas honestas, trabalhadoras, capazes de constituir e fazer amigos, e à escolarização imediata, diferentemente dos das crianças de ARA, cuja principal preocupação é com a escolarização futura e a possibilidade de a criança realizar uma faculdade.

Kellaghan, Sloane, Alvarez e Bloom (1993) referem, entre outras condições do ambiente familiar, relacionadas à aprendizagem escolar, que as aspirações acadêmicas e expectativas dos pais frente tanto às tarefas escolares quanto ao nível educacional e ocupacional exercem influência sobre a aprendizagem, uma vez que eles comunicam o nível instrucional e profissional que gostariam que seus filhos alcançassem, seja fazendo planos para o futuro ou investindo tempo e dinheiro para que as crianças possam realizar estas aspirações.

A presença de um número maior de recursos no 
ambiente familiar dos participantes do grupo ARA confirma outros dados da literatura que também indicam uma forte associação entre sucesso acadêmico e um ambiente rico em estimulação (Bradley \& cols., 1988; Grolnick \& Ryan, 1989; Cubero \& Moreno, 1995).

Vale acrescentar aqui que, as crianças do grupo ARA costumam com maior freqüência ter material de leitura em casa, o que favorece a habilidade para contar e inventar histórias, inclusive por ter mais contato com o material literário. Isto destaca que a presença de materiais educacionais na casa constitui-se num recurso favorecedor do desempenho escolar, especialmente quando associados ao envolvimento dos pais, participando e organizando a rotina da criança (Marturano, 1999).

No que diz respeito à participação da família na escola, um percentual maior de mães de crianças do grupo ARA freqüenta as reuniões escolares. Isto pode facilitar que elas identifiquem mais rapidamente as dificuldades acadêmicas de seus filhos e, então, ajudem a resolvê-las, evitando o desenvolvimento ou o agravamento de um problema.

Estes dados estão de acordo com outros relatados na literatura que destacam a importância do envolvimento dos pais na escola como favorecedor de um bom resultado quanto à aprendizagem escolar (Reynolds \& Bezruczko, 1993; Vickers, 1994; Magna \& Marturano, 1998; Marturano, Vincentim Alves \& Santa Maria, 1998).

Quanto às expectativas das mães frente ao futuro dos filhos, é interessante o fato de que parte das do grupo BRA tenha demonstrado preocupação em afastar ou evitar que a criança se envolvesse com violência, drogas, com o universo das ruas, talvez refletindo em suas expectativas o retrato da vizinhança onde moram. Com relação a esse aspecto também merece destaque a maior incidência no grupo ARA de esperanças de que as crianças realizem um curso superior, o que, novamente, está de acordo com dados da literatura que apontam uma associação entre nível educacional desejado pelos pais para seus filhos e desempenho acadêmico (Kellaghan \& cols., 1993). Snoldgrass (1991) refere que quando os pais ensinam o valor e a importância do estudo a seus filhos, estes tendem a desenvolver atitudes que os levam em direção ao sucesso escolar.

Chama atenção nos resultados deste trabalho que, de modo geral, foram poucas as diferenças entre os dois grupos de famílias, desmistificando um pouco a noção de que as de crianças com baixo rendimento são sempre pouco estruturadas, menos organizadas e orientam menos seus filhos. As práticas educativas são muito semelhantes, o que muda são as condições de vida, mais precárias ou menos confortáveis para as de crianças com baixo rendimento, e a educação e conhecimento dos pais que favoreçam o envolvimento deles nas atividades escolares dos filhos. Vale salientar que estes não são problemas que as famílias possam resolver sozinhas.

É importante comentar que este trabalho permitiu um contato próximo com as crianças, suas mães e professoras, todas se empenhando em colaborar e aproveitar a presença do pesquisador para tirar suas dúvidas, evidenciando a preocupação das mães e professoras com o desenvolvimento das crianças. Algumas vezes, esses adultos verbalizaram seu desconhecimento sobre como favorecer o processo de aprendizagem das criançcas, ao mesmo tempo, que seu desejo de fazer o melhor possível.

Finalmente, os resultados deste estudo reforçam a importância do papel da família e do ambiente em geral em proporcionar condições que estimulem o desenvolvimento infantil, ficando evidente a relevância de realização de trabalhos junto às famílias com o objetivo de ajudá-las a estruturar, organizar e enriquecer o ambiente de desenvolvimento da criança, muitas vezes utilizando recursos já existentes.

\section{Referências Bibliográficas}

Baldwin, A . L., Baldwin, C. \& Cole, R. (1990). Stressresistant children and stress-resistant families. Em J. Rolf.; A. S. Masten.; D. Cicchetti; K. H. Nuechterlein \& S. Weintraub (Eds.), Risk and protective factors in the development of psychopathology (pp.257-280). Cambridge: Cambridge University Press.

Benasich, A. A. \& Brooks-Gunn, J. (1996). Maternal attitudes and knowledge of child-rearing: associations with family and child outcomes. Child Development, 67, 1186-1205.

Bendersky, M. \& Lewis, M. (1994). Environmental risk, biological risk, and developmental outcome. Developmental Psychology, 30 (4), 484-494.

Bradley, R. H.; Caldwell, B. M. \& Rock, S. L. (1988). Home environment and school performance: a tem-year follow- 


\section{6}

\section{Patricia Leila dos Santos}

up and examination of three models of environmental action. Child Development, 59, 852-867.

Bradley, R. H. \& Corwyn, R. F. (2002). Socieconomic status and child development. Annual Review of Psychology, 53, 371-399.

Cubero, R. \& Moreno, M. C. (1995). Relações sociais nos anos escolares: família, escola, companheiros. Em C. Coll, J. Palacios \& A . Marchesi (Orgs.), Desenvolvimento psicológico e educação: psicologia evolutiva (pp.250-260). Porto Alegre: Editora Artes Médicas.

Duncan, G. J; Brooks-Gunn, J. \& Klebanov, P. K. (1994). Economic deprivation and early childhood development. Child Development, 65, 296-318.

Farran, D. C. \& Cooper, D. H. (1986). Psychosocial risk: which early experiences are important for whom? Em D. C. Farran \& J. D. McKinney, (Orgs.), Risk in intellectual and psychosocial development (pp.187226). Orlando: Academic Press.

Graminha, S. S. V.; Martins, M. A . de O . \& Miura, R. T. (1996). Fatores potenciais de risco em crianças com problemas emocionais/comportamentais. Psico, 7 (2), 46-57.

Grolnick, W. S. \& Ryan, R. M. (1989). Parent styles associated with children's self-regulation and competence in school. Journal of Educational Psychology, 84, 143-154.

Kellaghan, T.; Sloane, K.; Alvarez, B. \& Bloom, B. S. (1993). A process-based approach for homes. Em T. Kellaghan; K. Sloane; B. Alvarez; \& B. S. Bloom, (Orgs.), The home environment and school learning: promoting parental involvement in the education of children (pp.136-143). San Francisco: Jossey-Bass Pub.

Lewis, R. J.; Dlugokinski, E. L.; Caputo, L. M. \& Griffin, R. B. (1988). Children at risk for emotional disorders: risk and resource dimensions. Clinical Psychology Review, 8, 417- 440.

Magna, J. M. (1997). Atraso escolar: um levantamento de condições de desenvolvimento antecedentes à entrada na primeira série. Dissertação de Mestrado não publicada. Faculdade de Medicina de Ribeirão Preto, Universidade de São Paulo, Ribeirão Preto.

Magna, J. M. \& Marturano, E. M. (1998). Atraso escolar: um levantamento de condições de desenvolvimento antecedentes à entrada na $1^{\mathrm{a}}$. série. Em A . W. Zuardi, E. M. Marturano, M. A . de C. Figueiredo e S. R. Loureiro, (Orgs.), Estudos em Saúde Mental (pp. 9-
47). Ribeirão Preto: Pós-Graduação em Saúde Mental da FMRP/USP.

Marturano, E. M. (1999). Recursos no ambiente familiar e dificuldades de aprendizagem na escola. Psicologia: Teoria e Pesquisa, 15, (2), 135-142.

Marturano, E. M.; Magna, J. C. \& Murtha, P. C. (1993). Procura de atendimento psicológico para crianças com dificuldades escolares: um perfil da clientela. Psicologia: Teoria e Pesquisa, 9 (1), 207-226.

Marturano, E. M.; Vincentim Alves, M. A . \& Santa Maria, M. R. (1998). Recursos do ambiente familiar e desempenho na escola. Em A. W. Zuardi, E. M. Marturano, M. A . de C. Figueiredo e S. R. Loureiro, (Orgs.), Estudos em Saúde Mental (pp.48-77). Ribeirão Preto: PósGraduação em Saúde Mental da FMRP/USP.

Reynolds, A. J. \& Bezruczko, N. (1993). School adjustment of children at risk through fourth grade. Merrill-Palmer Quartely, 39 (4), 457-480.

Rutter, M. (1987). Psychosocial resilience and protective mechanisms. American Journal of Orthopsychiatry, 57 (3), 316-331.

Santos, P. L. (2002). Riscos e recursos em crianças com baixo e alto rendimento acadêmico - um estudo comparativo. Tese de Doutorado não publicada. Faculdade de Filosofia, Ciências e Letras de Ribeirão Preto, Universidade de São Paulo, Ribeirão Preto.

Snoldgrass, D. M. (1991). The parent connection. Adolescence, 26 (101), 83-87.

Speakman, N. J.; Herman, K. L. \& Vogel, S. A. (1993). Risk and resilience in individuals with learning disabilities: a challenge to the field. Learning Disabilities: Research \& Practice, 8(1), 59-65.

Vickers, H. S. (1994). Young children at risk: differences in family functioning. Journal of Educational Research, 87 (5), 262-270.

Weiss, M. L. L. (1997). Psicopedagogia Clínica - uma visão diagnóstica dos problemas de aprendizagem escolar. Rio de Janeiro: DP\&A.

Wood, D.; Halfon, N.; Scarlata, D.; Newacheck, P. \& Nessim, S. (1993). Impact of relocation on children's growth, development, school function, and behavior. JAMA, 270 (11), 1334-1338.

Trabalho derivado da Tese de Doutorado do primeiro autor. 